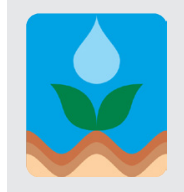

\author{
Revista Brasileira de Engenharia Agrícola e Ambiental \\ v.18, n.9, p.920-926, 2014 \\ Campina Grande, PB, UAEA/UFCG - http://www.agriambi.com.br \\ Protocolo 275.13 - 30/08/2013 • Aprovado em 18/04/2014
}

\title{
Uso da terra e atributos de solos do estado do Rio Grande do Sul
}

\author{
Paulo C. do Nascimento ${ }^{1}$, Carlos A. Bissani², Renato Levien ${ }^{3}$, Marno E. Losekann ${ }^{4}$ \& Tatiana Finato ${ }^{5}$ \\ ${ }^{1}$ Departamento de Solos, Faculdade de Agronomia/UFRGS. Porto Alegre, RS. E-mail: 00009911@ufrgs.br (Autor correspondente) \\ ${ }^{2}$ Departamento de Solos, Faculdade de Agronomia/UFRGS. Porto Alegre, RS. E-mail: carlos.bissani@ufrgs.br \\ ${ }^{3}$ Departamento de Solos, Faculdade de Agronomia/UFRGS. Porto Alegre, RS. E-mail: renatole@ufrgs.br \\ ${ }^{4}$ INCRA. Manaus, AM. E-mail: marnolosekann@ibest.com.br \\ ${ }^{5}$ Secretaria de Desevolvimeto Rural - Governo do Estado do Rio Grande do Sul. Porto Alegre, RS. E-mail: tatifinato@yahoo.com.br
}

\section{Palavras-chave:}

sistemas de produção

produção agroecológica

uso e manejo do solo

\begin{abstract}
R E S U M O
A região da Encosta Inferior do Nordeste, no estado do Rio Grande do Sul, apresenta, na atividade agrícola, variações no tipo de uso do solo e sistemas de produção podendo levar à diferenciação nos atributos do solo e a processos de degradação. Com o objetivo de avaliar a granulometria e os atributos químicos do solo e compará-los em diferentes tipos de uso e manejo 78 glebas foram amostradas com oito diferentes tipos de uso, em sistemas de produção convencional e de base agroecológica (orgânico) entre 2009 e 2010 enquanto amostras de solo foram coletadas na camada de 0 a $20 \mathrm{~cm}$ e realizadas determinações de uma série de atributos. Os resultados destacaram, entre outros, o pH, a condutividade elétrica e os teores de zinco e fósforo com maiores valores no uso com olericultura convencional; por sua vez, o enxofre apresentou maiores teores nas áreas de viticultura. A aplicação de análise discriminante indicou que $67 \%$ das glebas tiveram enquadramento em seus usos definidos por ocasião da amostragem (originais) e a análise de componentes principais ressaltou maior semelhança entre os tipos de uso em sistema orgânico e na lavoura convencional. Alguns elementos apresentaram teores bastante altos indicando um potencial de contaminação e degradação ambiental.
\end{abstract}

Key words:

production systems agroecological production soil use and management

\section{Land use and attributes of soils of the state of Rio Grande do Sul}

\begin{abstract}
A B S T R A C T
Lower northeast hillside region, in Rio Grande do Sul state, Brazil, shows, in agricultural activities, variability in soil use and production systems, which can result in change of soil attributes and degradation processes. With the aim to evaluate particle size distribution and chemical attributes and to compare them in different soil use and management system, soil samples from 78 areas, performing eight diverse types of soil use in conventional and organic production systems, were sampled for the study, between 2009 and 2010. Soil samples were collected at 0 to $20 \mathrm{~cm}$ depth, and a series of attributes were determined. Results showed $\mathrm{pH}$, electrical conductivity, zinc and phosphorus contents with higher values in areas of conventional vegetable production, while sulphur showed higher values in soil under grape cultivation. Discriminate analysis indicated that $67 \%$ of the areas were classified in the same use defined at the time of sampling (original use), and principal component analysis showed more similar behavior among uses in organic system, besides conventional crop. Some elements showed very high contents, indicating potential contamination and environmental risk.
\end{abstract}

\section{INTRODUÇÃo}

A busca por sistemas sustentáveis de produção agrícola tem resultado no aumento da adoção de formas de uso e manejo do solo que resultem em menor impacto ambiental, tal como na utilização de indicadores que, em médio prazo, possam contribuir na avaliação da sustentabilidade desses sistemas. Neste contexto, a sustentabilidade pode ser estimada, entre outros, pela avaliação e monitoramento de atributos do solo sensíveis a alterações pelo uso e manejo ao longo do tempo a partir dos quais se avalia a evolução da qualidade do solo. Referidos atributos englobam características físicas, químicas e biológicas com reflexos na qualidade dos recursos naturais, dentro do ambiente em que se inserem e na qualidade de vida dos produtores e comunidades envolvidas (Vezzani \& Mielniczuk, 2009).

A região da Encosta Inferior do Nordeste do estado do Rio Grande do Sul abrange grande parte do vale do Rio Caí, inserida em uma região de transição entre diferentes regiões fisiográficas do estado do Rio Grande do Sul. Apresenta um perfil de produção agrícola de importância socioeconômica, com destaque para a olericultura e a produção de morango. As fontes de contaminação das águas da bacia hidrográfica são originadas, em parte, do uso dos solos em atividades agropecuárias principalmente de insumos em geral (FEPAM, 2013). As características dos sistemas de produção indicam, desta forma, o potencial econômico e social da atividade agrícola e, por outro lado, a vulnerabilidade a processos de 
degradação dos recursos naturais. Estudos realizados em diversas regiões do estado do Rio Grande do Sul indicam problemas potenciais ou mesmo já estabelecidos, relacionados a alterações em características do solo a partir de conflitos de uso e manejo (Klamt et al., 1995; Nascimento et al., 2013). Esses dados indicam, por sua vez, a necessidade de avaliação das características dos solos e do ambiente em geral, com ênfase nas suas limitações e potencialidades, para o estabelecimento de atividades agrícolas (Pedron et al., 2006).

Com base no exposto, o presente trabalho parte da hipótese de que solos semelhantes em relação à formação e características originais têm sofrido alterações relacionadas ao uso e aos sistemas de produção podendo, em alguns casos, representar situações de degradação e risco ambiental. Assim, os objetivos principais são: i) caracterizar os solos utilizados em sistemas de produção definidos como "convencional" e "orgânico", em camada de 0 a $20 \mathrm{~cm}$, em relação aos atributos físicos (granulometria) e químicos; ii) comparar esses atributos entre os diferentes usos e sistemas de produção analisados; iii) estimar prováveis processos de degradação presentes nesses solos, além de alterações que possam constituir ameaça à qualidade dos demais recursos naturais.

\section{MATERiAl E Métodos}

A Encosta Inferior do Nordeste é caracterizada como região fisiográfica do estado do Rio Grande do Sul (RS) ocupando uma posição de transição entre a região do Planalto e a Depressão Central (Figura 1).

O relevo é ondulado a forte ondulado com geologia ligada à Formação Serra Geral (basalto de granulação média a fina) tendo, na porção mais ao sul, relevo suavizado associado a materiais sedimentares (arenito, folhelhos e siltitos) do grupo Rosário do Sul e formação Botucatu. A vegetação é de floresta estacional semidecidual com algum contato com floresta de araucárias (CPRM, 2006). O clima é subtropical úmido com transição entre $\mathrm{Cfa}$ e $\mathrm{Cfb}$ tendo o primeiro temperaturas médias superiores a $22^{\circ} \mathrm{C}$ para o verão e a precipitação anual está entre 1.500 e $1.750 \mathrm{~mm}$. As principais unidades taxonômicas de solos são Chernossolos Háplicos, Chernossolos Argilúvicos, Nitossolos Vermelhos, e Neossolo Litólico nas áreas de basalto

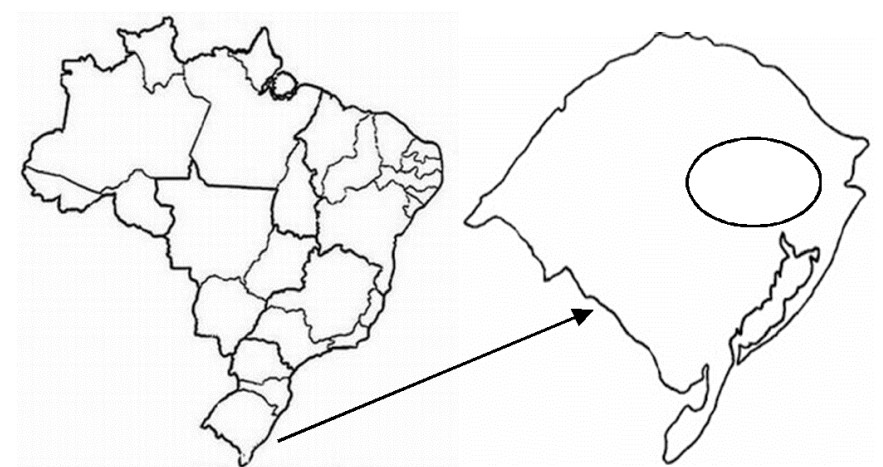

Figura 1. Mapas do Brasil e do Rio Grande do Sul com destaque, no último, para localização aproximada da Encosta Inferior do Nordeste
(Streck et al., 2008). Os municípios nos quais se realizou o trabalho são os de Picada Café, Bom Princípio e Feliz, circunscritos nas coordenadas UTM 462000 e 490000 e 6738000 e 6748000. A agricultura familiar se expressa sobremaneira em aspectos como o tamanho médio das propriedades rurais, a diversificação da produção e a mão-de-obra atuante (Waquil et al., 2005). O trabalho foi realizado durante os anos de 2009 e 2010 em nove unidades de produção (UPs) da região, com sistemas de produção convencional ou de base agroecológica aqui denominados "orgânico". Mencionadas propriedades foram escolhidas aleatoriamente, com base em observações de imagens de satélite ("Google Earth") e em percorrimento da área.

Para a coleta de amostras de solo foram escolhidas 78 glebas com sistemas de uso e manejo da terra (denominados "tipos de uso") praticados há pelo menos cinco anos e que contemplam oito diferentes situações, a saber: (1) olericultura (incluindo morango) em sistema de produção orgânico, com 10 glebas amostradas; (2) olericultura (incluindo morango) em sistema de produção convencional, com 10 glebas amostradas; (3) fruticultura em sistema de produção orgânico, com 7 glebas amostradas; (4) fruticultura em sistema de produção convencional, com 8 glebas amostradas; (5) lavoura (culturas anuais em geral) em sistema de produção orgânico, com 13 glebas amostradas; (6) lavoura em sistema de produção convencional, com 9 glebas amostradas; (7) viticultura em sistema de produção orgânico, com 10 glebas amostradas. Além desses tipos de uso áreas com mata nativa, sem influência humana há pelo menos 20 anos, em número de 11, também foram utilizadas para amostragem sendo referidas como o tipo de uso (8). As glebas utilizadas apresentavam, como características gerais, extensão variando de 0,2 a 1,5 ha, com declividade entre 8 e $20 \%$. Os solos apresentam teor mínimo de argila de $200 \mathrm{~g} \mathrm{~kg}^{-1}$.

Os sistemas de produção adotados diferem entre si em procedimentos para preparo do solo, adubação e tratamentos fitossanitários. No sistema de produção orgânico a adubação utilizada era composta, basicamente, de composto orgânico com esterco de aves e bovino em quantidades aproximadas de 30 a $40 \mathrm{~m}^{3} \mathrm{ha}^{-1}$ por ano; cinzas da queima de madeira, fosfato natural e também adubação via foliar com aplicação de "super-magro" (biofertilizante utilizado na agricultura orgânica provindo da mistura e da fermentação de ingredientes, tais como melado, leite, esterco fresco de bovinos e água).

Em geral, o manejo das áreas é caracterizado pela pouca mobilização do solo em operações de preparo, com exceção das áreas de olericultura. Nas áreas de lavoura adota a rotação de culturas com predomínio de milho, feijão e aveia em sucessão verão - inverno e também glebas sob cultivo de alfafa, em primeiro ou segundo ano, cobertura do solo com resíduos da cultura antecessora e espécies utilizadas para cobertura verde. Não é utilizada adubação com NPK porém ocorre a aplicação eventual de calcário. Observa-se que alguns agricultores estão em processo de substituição de práticas e insumos podendose caracterizá-lo como transição para o modelo de produção agroecológico (Finatto \& Salamoni, 2008). 
Os sistemas de produção convencional se caracterizavam pela utilização de adubos minerais, sobretudo em cobertura, para suprimento de $\mathrm{N}$ e $\mathrm{K}$ em quantidades que chegam a 100 $\mathrm{kg}$ de $\mathrm{N} \mathrm{ha}^{-1}$ e $200 \mathrm{~kg}$ de $\mathrm{K}_{2} \mathrm{O} \mathrm{ha}^{-1}$. A adubação orgânica também é praticada utilizando-se composto em quantidades de até 50 $\mathrm{m}^{3} \mathrm{ha}^{-1}$ na formação dos canteiros para olerícolas e também na fruticultura, em menor quantidade. O preparo do solo é feito utilizando-se principalmente o arado de aiveca ou de discos, seguido de grade niveladora. Na época de amostragem, na maior parte dos casos nos meses de março a junho, os produtores declararam que, ainda não tinham procedido à adubação, que variou entre seis e doze meses antes da coleta.

As coletas de amostras de solo foram realizadas com trado holandês, na profundidade de $0-20 \mathrm{~cm}$. Em cada gleba amostrada foram coletadas de oito a dez subamostras resultando em uma amostra composta. No laboratório as amostras foram secadas e destorroadas, obtendo-se a terra fina secada ao ar (diâmetro máximo de 2,0 mm) por peneiramento. Os atributos do solo determinados foram o teor de argila, por meio de análise granulométrica utilizando-se o método do densímetro, conforme EMBRAPA (1997); pH em água; acidez extraível $\left(\mathrm{H}^{+} \mathrm{e}\right.$ $\mathrm{Al}^{3+}$ ) - extraída com acetato de cálcio a $\mathrm{pH} 7$ e determinada por titulação; $\mathrm{Ca}^{2+}, \mathrm{Mg}^{2+}, \mathrm{Na}^{+}$e $\mathrm{K}^{+}$trocáveis (EMBRAPA, 1997). Com esses dados foram calculadas a capacidade de troca catiônica (CTC a pH 7,0) e a saturação por bases (V) a partir da soma de bases (Sb) conforme EMBRAPA (1997).

Foram avaliados, ainda, o fósforo (P) disponível, extraído por Mehlich-1, com determinação por colorimetria, e os teores de $\mathrm{Mn}, \mathrm{Zn}$ e $\mathrm{Cu}$ com extração por Mehlich modificado e determinação por espectrofotometria de absorção atômica; condutividade elétrica (CE) em extrato solo:água na proporção 1:1; carbono orgânico (CO) pelo método de oxidação ácida (EMBRAPA, 1997). O carbono orgânico particulado (COP) foi determinado por fracionamento granulométrico, conforme Gregorich \& Ellert (1993). O enxofre (S) foi determinado por extração em solução de fosfato de cálcio com determinação por turbidimetria enquanto o boro foi extraído por água quente com determinação por colorimetria (Tedesco et al., 1995; EMBRAPA, 1997). As determinações foram feitas em duplicata com a obtenção do valor médio.

A análise estatística foi feita por meio da utilização do programa SPSS (Social Package for Social Sciences) ${ }^{\circledR}$, utilizandose, como variáveis, os teores de argila, $\mathrm{COP}, \mathrm{CO}, \mathrm{S}, \mathrm{Mn}, \mathrm{Cu}, \mathrm{Zn}$, $\mathrm{B}$ e $\mathrm{P}$, além do $\mathrm{pH}, \mathrm{CE}, \mathrm{CTC}$ e $\mathrm{Sb}$. As análises foram realizadas para cada atributo, por meio de comparação entre médias dos tratamentos (tipos de uso) e, em caso de diferenças entre esses, as médias foram comparadas pelo teste de Tukey a 0,05 de significância.

As análises multivariadas foram realizadas a partir da constituição de matriz com 78 amostras e 13 variáveis e constaram da análise discriminante para avaliação do comportamento de cada unidade amostral procedendo-se à reclassificação com enquadramento em um dos tipos de uso, por meio da verificação de semelhança entre a amostra e o conjunto de amostras de cada tipo de uso. Foi feita, também, a extração de componentes principais (CPs) com definição das médias dos escores para cada CP em cada tipo de uso, além de análise de agrupamentos hierárquicos entre os mesmos, a partir do cálculo da distância euclidiana ponderada definindo tipos de uso com maior semelhança entre si (Freddi et al., 2008).

\section{Resultados e Discussão}

O P e o Mn apresentaram ausência de normalidade na distribuição, o que foi corrigido por meio da transformação de dados para base logarítmica. A avaliação entre os tratamentos para os atributos teor de argila, capacidade de troca de cátions (CTC), soma de bases (Sb), teores de carbono orgânico total (CO) e carbono orgânico particulado (COP) não indicou diferenças significativas para o nível de significância avaliado (dados não apresentados). Os teores médios de argila variaram dentro de uma amplitude de 250 a $360 \mathrm{~g} \mathrm{~kg}^{-1}$. Os teores de $\mathrm{CO}$ e COP indicaram tendência de diferenças entre tipos de uso com maiores teores para as glebas com mata nativa, reforçando a tendência à diminuição dos teores de carbono orgânico a partir da incorporação das áreas em atividades intensivas de produção (Costa et al., 2008).

Os maiores valores de $\mathrm{pH}$ e condutividade elétrica (CE) foram encontrados na olericultura convencional (Figura 2) na

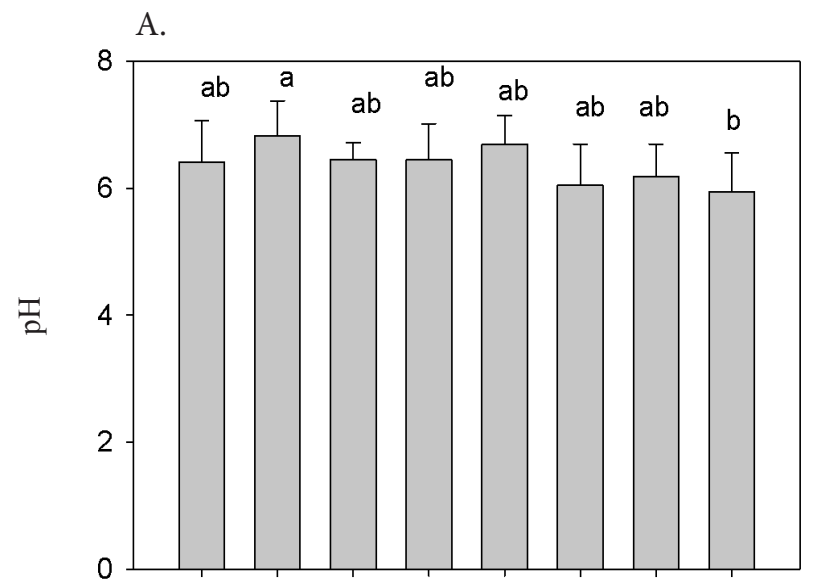

B.

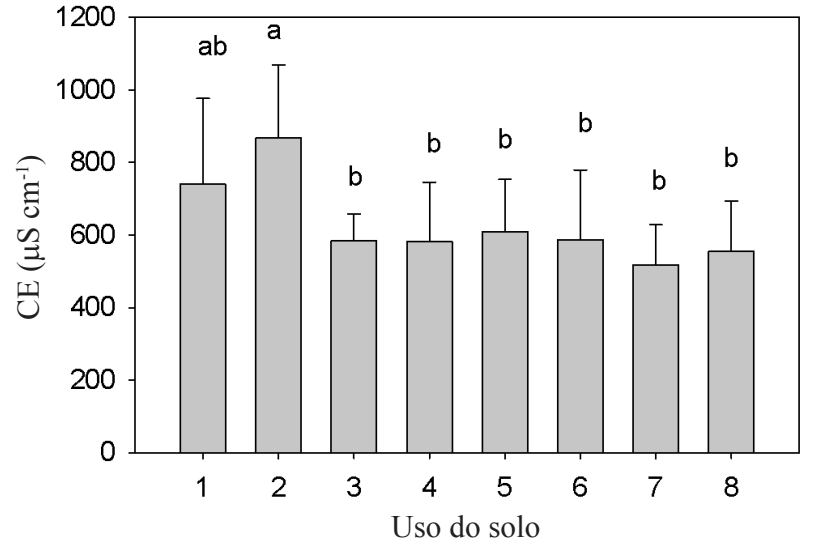

1 - Olericultura orgânica; 2 - Olericultura convencional; 3 - Fruticultura orgânica; 4 - Fritucultura convencional; 5 - Lavoura orgânica; 6 - Lavoura convencional; 7 - Viticultura; 8 - Mata nativa; Letras iguas indicam as diferenças significativas a partir do teste de Tukey em nivel de 0,05 de probabilidade. Mesmas letras indicam ausência de diferenças significativas

Figura 2. Valores de $\mathrm{pH}(\mathrm{A})$ e condutividade elétrica (CE) (B) para os diferentes tipos de uso 
qual as práticas de calagem e adubação mineral e orgânica foram realizadas em maiores quantidades. Em relação ao pH (Figura $2 \mathrm{~A})$ as áreas com olericultura convencional apresentaram valores levemente ácidos (Bissani et al., 2008) diferindo da mata nativa e evidenciando os efeitos de uso e manejo.

Neste sistema as práticas de adubação e calagem concentradas na área de formação dos canteiros resultaram em altos valores também na condutividade elétrica (Figura 2B). Neste atributo a olericultura convencional não difere apenas deste mesmo uso em sistema de produção orgânico. O efeito de adubação mineral e/ou orgânica aplicadas em grandes quantidades parece exercer maior influência para o aumento da CE; este efeito se repete, também, para os teores de Zn (Borges \& Coutinho, 2004) como se observa na Tabela 1.

Nos teores de $\mathrm{Cu}$ não houve diferença significativa entre usos mas se supõe que características dos solos trabalhados com textura média a argilosa e participação expressiva de óxidos de ferro na composição mineralógica, favorecem a retenção do $\mathrm{Cu}$ em formas de menor mobilidade (Alleoni et al., 2005). Ressalta-se, porém, que os teores desses elementos excederam em cerca de oito $(\mathrm{Cu})$ até quarenta vezes $(\mathrm{Zn})$ o limite para a classe "alto" estabelecida por CFS (2004) indicando possíveis problemas de contaminação dos solos.

As diferenças significativas para o enxofre (S) indicam maior aporte no uso com viticultura levando a teores que excedem em cerca de cinco vezes o limite da classe "alto" para teores deste elemento (CFS, 2004). Verificam-se maiores teores de $\mathrm{S}$ em sistemas de produção orgânicos, além da olericultura convencional. A utilização deste elemento é bastante associada à viticultura, inclusive por meio de produtos para proteção fitossanitária, entre as quais se destacam as denominadas "caldas de preparo caseiro", como sulfocálcica ou "bordaleza" (Peruch \& Bruna, 2008) podendo ser também o caso do boro (B) cuja viticultura orgânica teve maiores valores. O Mn, por sua vez, apresenta tendência contrária da maior parte dos elementos avaliados com maiores teores nas áreas com mata nativa, apresentando diferenças significativas em relação à viticultura, lavoura e fruticultura em sistemas orgânicos e olerícolas em sistema convencional, provavelmente pela grande adição de nutrientes nesses usos, influenciando o complexo sortivo.

$\mathrm{O}$ fósforo $(\mathrm{P})$ apresenta comportamento importante entre as diferentes formas de uso e o manejo do solo devido à sua grande utilização nesses sistemas (Figura 3). Os usos mais intensivos do solo apresentaram, como consequência, teores de P que excedem em quatro a cinco vezes o limite para a classe de teores "muito alta" para este elemento, chegando a dez vezes este limite para olericultura convencional. Destacam-se, neste caso, as grandes concentrações de fósforo nos principais componentes orgânicos utilizados, como cama de frango e esterco bovino, ao contrário de efluentes e materiais residuários (Duarte et al., 2012). A olericultura convencional apresentou os maiores teores de P diferindo dos valores obtidos para viticultura e mata nativa. As características desses solos (originados de basalto, com textura média a argilosa) e o método de extração do P, indicam que este elemento foi adicionado sob formas orgânicas, mas permanece no solo após a mineralização (Novais \& Smyth, 1999; Schmitt et al., 2013).

A aplicação de adubos orgânicos a partir de compostos com esterco animal tem resultado em aumentos de fósforo em formas variáveis quanto à labilidade (Andreola et al., 2000; Souza et al., 2007). Os teores de P encontrados se encontram abaixo da capacidade máxima de adsorção para grande parte dos solos de regiões subtropicais (Vilar et al., 2010). Avalia-se, porém, que a aplicação continuada de adubos orgânicos e minerais pode resultar, nessas taxas, em problema de perdas de fósforo sob formas de sedimentos e problemas de ordem ambiental, como poluição de mananciais hídricos (Giasson et al., 2002).

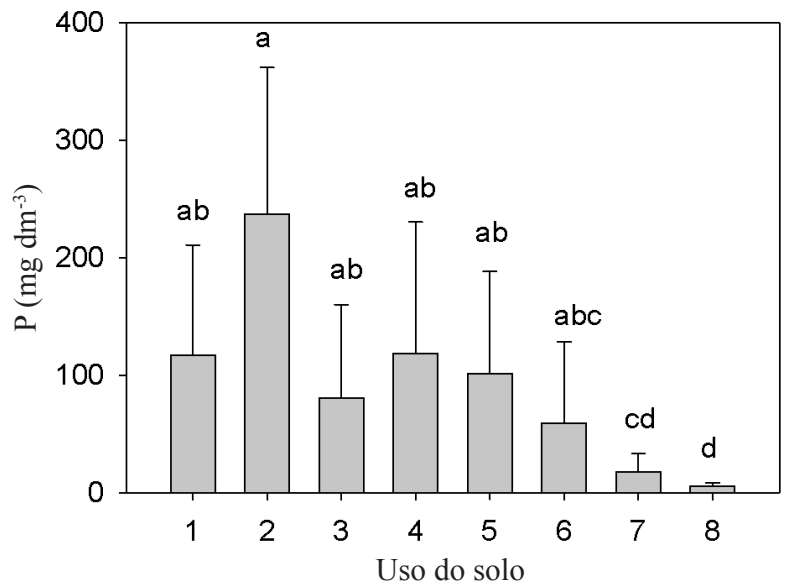

1 - Olericultura orgânica; 2 - Olericultura convencional; 3 - Fruticultura orgânica; 4 - Fritucultura convencional; 5 - Lavoura orgânica; 6 - Lavoura convencional; 7 - Viticultura; 8 - Mata nativa; Letras indicam as diferenças significativas a partir do teste de Tukey em nivel de 0,05 de probabilidade. Mesmas letras indicam ausência de diferenças significativa

Figura 3. Teores de fósforo no solo, com valores originais (sem conversão para base logarítmica) para os tipos de uso

Tabela 1. Teores de enxofre e micronutrientes para os diferentes tipos de uso do solo

\begin{tabular}{|c|c|c|c|c|c|c|c|c|c|c|}
\hline \multirow{3}{*}{ Tratamento } & \multicolumn{2}{|c|}{$S$} & \multicolumn{2}{|c|}{$M n^{*}$} & \multicolumn{2}{|c|}{ B } & \multicolumn{2}{|c|}{$\mathrm{Zn}$} & \multicolumn{2}{|c|}{$\mathrm{Cu}$} \\
\hline & Média & D. pad & Média & D. pad & Média & D. pad & Média & D. pad & Média & D. pad \\
\hline & \multicolumn{10}{|c|}{$\mathrm{mg} \mathrm{kg}^{-1}$} \\
\hline Ol-org & $19,8 a b$ & 10,6 & $17,2 a b$ & 18,3 & $0,55 a b$ & 0,16 & $12,1 \mathrm{~b}$ & 7,95 & 2,9 & 1,20 \\
\hline Ol-con & $23,4 a b$ & 24,3 & $9,0 \mathrm{~b}$ & 11,8 & $0,46 a b$ & 0,07 & $22,3 \mathrm{a}$ & 7,68 & 2,0 & 1,91 \\
\hline Fr-org & $20,8 a b$ & 8,8 & $13,0 \mathrm{~b}$ & 28,2 & $0,54 a b$ & 0,05 & $12,0 \mathrm{~b}$ & 5,33 & 3,5 & 0,81 \\
\hline Fr-con. & $8,7 \mathrm{~b}$ & 2,5 & $46,3 a b$ & 55,5 & $0,43 \mathrm{~b}$ & 0,05 & $7,8 \mathrm{~b}$ & 4,40 & 2,2 & 1,22 \\
\hline Lv-org & $19,5 a b$ & 11,3 & $7,9 \mathrm{~b}$ & 9,9 & $0,53 a b$ & 0,12 & $10,6 \mathrm{~b}$ & 5,55 & 2,1 & 1,13 \\
\hline LV-con & $8,5 \mathrm{~b}$ & 4,5 & $17,2 a b$ & 19,4 & $0,53 a b$ & 0,18 & $9,7 \mathrm{~b}$ & 3,89 & 4,1 & 3,00 \\
\hline Vit-org & $27,9 \mathrm{a}$ & 13,7 & $14,5 \mathrm{~b}$ & 22,6 & $0,59 a$ & 0,06 & $5,0 \mathrm{~b}$ & 2,89 & 2,9 & 1,01 \\
\hline Mata nat & $14.8 \mathrm{ab}$ & 116 & $54.6 \mathrm{a}$ & 44.1 & $0.54 a b$ & 0.09 & $77 \mathrm{~b}$ & 7.37 & 2.1 & 0.81 \\
\hline
\end{tabular}

d. pad - Desvios-padrão; Ol - Olericultura; Fr - Fruticultura; Lv - Lavoura; Vit - Viticultura; com - Convencional; org - Orgânica; Valores originais, sem conversão para logaritmo; As letras indicam as diferenças estatísticas pelo teste de Tukey em nível de 0,05 de probabilidade. Ausência de letras indica ausência de diferenças significativas 
Tabela 2. Matriz de erros no enquadramento dos pontos de amostragem para os tipos de uso do solo, com base em funções discriminantes

\begin{tabular}{lccccccccc}
\hline & Ol-org & Ol-con & Fr-org & Fr-com & Lv-org & Lv-con & Viti & Mata & C0 \\
Ol-org & $\mathbf{4}$ & 1 & 3 & 0 & 1 & 0 & 1 & 0 & 10 \\
Ol-con & 0 & $\mathbf{9}$ & 0 & 1 & 0 & 0 & 0 & 0 & 10 \\
Fr-org & 0 & 1 & $\mathbf{5}$ & 0 & 0 & 0 & 1 & 0 & 7 \\
Fr-con & 1 & 0 & 0 & $\mathbf{6}$ & 0 & 0 & 0 & 1 & 8 \\
Lv- org & 1 & 0 & 1 & 0 & $\mathbf{8}$ & 0 & 3 & 0 & 13 \\
Lv- con & 1 & 1 & 1 & 1 & 0 & $\mathbf{5}$ & 0 & 0 & 9 \\
Viti & 0 & 0 & 2 & 0 & 1 & 0 & $\mathbf{6}$ & 1 & 10 \\
Mata & 1 & 0 & 0 & 0 & 0 & 0 & 1 & $\mathbf{9}$ & 11 \\
AD & 8 & 12 & 12 & 8 & 10 & 5 & 12 & 11 & 78 \\
\hline
\end{tabular}

OI - Olericultura; Fr - Fruticultura; Lv - Lavoura; Vit - Viticultura; com - Convencional; org - Orgânica

A análise discriminante possibilitou o enquadramento de cada unidade amostral (parcela) em cada tipo de uso, com base na utilização de três funções discriminantes, que corresponderam a $82 \%$ da variância acumulada a partir dos 13 atributos avaliados (Tabela 2). Entre as 78 amostras trabalhadas 52 tiveram a classificação pela análise discriminante (AD) coincidente com a classificação original (CO) feita por ocasião da identificação da gleba e da realização da amostragem. Este dado indica exatidão geral de $67 \%$. Os denominados erros de omissão - EO (atribuição de glebas como sendo de outros tratamentos e não como o tratamento original) foram maiores na olericultura orgânica quando apenas $40 \%$ das amostras tiveram a classificação por $\mathrm{AD}$ coincidente com CO. O índice de Kappa foi de 0,62, considerado bom, evidenciando coincidência entre as classificações por $\mathrm{AD}$ e a $\mathrm{CO}$ (Figueiredo et al., 2008).

A análise dos componentes principais (CP) foi feita a partir de 11 atributos já que os teores de COP e $\mathrm{Cu}$ foram eliminados da análise em razão de apresentarem as menores diferenças entre tratamentos. A análise dos autovalores assumidos pelos componentes principais, com seleção dos que obtiveram valores maiores que 1,0 , bem como o percentual da variância representado por esses, permitiu a seleção de $3 \mathrm{CPs}$, correspondendo a $70 \%$ da variância total. A Tabela 3 indica as correlações obtidas entre os CPs e as variáveis originais. $\mathrm{O}$ $\mathrm{CP} 1$ está relacionado às características do complexo sortivo (soma de bases e CTC) além do enxofre (S); o CP 2 sinaliza alta correlação com características da solução do solo, como $\mathrm{pH}$ e condutividade elétrica, além do fósforo, enquanto o CP 3 apresentou maior correlação com o boro e o carbono orgânico.

Tabela 3. Coeficientes de correlação entre variáveis originais e componentes principais extraídos

\begin{tabular}{lccc}
\hline Variáveis & \multicolumn{3}{c}{ Componentes principais } \\
\cline { 2 - 4 } originais & CP 1 & CP 2 & CP 3 \\
Argila & 0,50 & $-0,42$ & $-0,010$ \\
pH & 0,47 & 0,71 & -0.100 \\
C orgânico & 0,08 & 0,06 & 0,710 \\
CTC & 0,90 & 0,06 & 0,260 \\
Sb & 0,92 & 0,16 & 0,230 \\
S & 0,71 & 0,00 & $-0,270$ \\
Zn & $-0,23$ & 0,80 & 0,223 \\
B & $-0,03$ & $-0,26$ & $-0,800$ \\
CE & 0,14 & 0,80 & 0,050 \\
P (log) & 0,03 & 0,80 & 0,180 \\
Mn (log) & $-0,57$ & $-0,49$ & 0,540 \\
\hline
\end{tabular}

Com base nos escores médios obtidos pelos tipos de uso para cada $\mathrm{CP}$, obteve-se seu grupamento hierárquico (Figura 4). Observam-se as maiores semelhanças entre olericultura, fruticultura e lavouras no sistema orgânico e lavoura convencional. Avalia-se que os sistemas de produção utilizados, principalmente em relação à adubação com composto orgânico influenciaram, em grande escala, este comportamento. A princípio, pode-se avaliar os usos sob lavouras e olericultura como de maior intensidade em termos de preparo de solo e aplicação de adubos, em relação à fruticultura, porém as características dos solos, com teores médios a altos de argila e a constituição com participação de óxidos de ferro, resultam em maior estabilidade na presença de elementos como cátions básicos e $\mathrm{P}$, além da matéria orgânica, tornando semelhantes os efeitos desses tipos de uso. O emprego de insumos de forma menos intensiva nas glebas com lavouras convencionais em razão das próprias condições das UPs e da finalidade dos cultivos (boa parte para autoconsumo ou alimentação de criações) também serviu para aproximar este tipo de uso aos de alguns sistemas orgânicos.

Correa et al. (2009) também utilizaram os escores dos CPs para agrupar tipos de uso do solo distinguindo-os com base em graus de degradação do solo. Lima et al. (2007) e Theodoro et

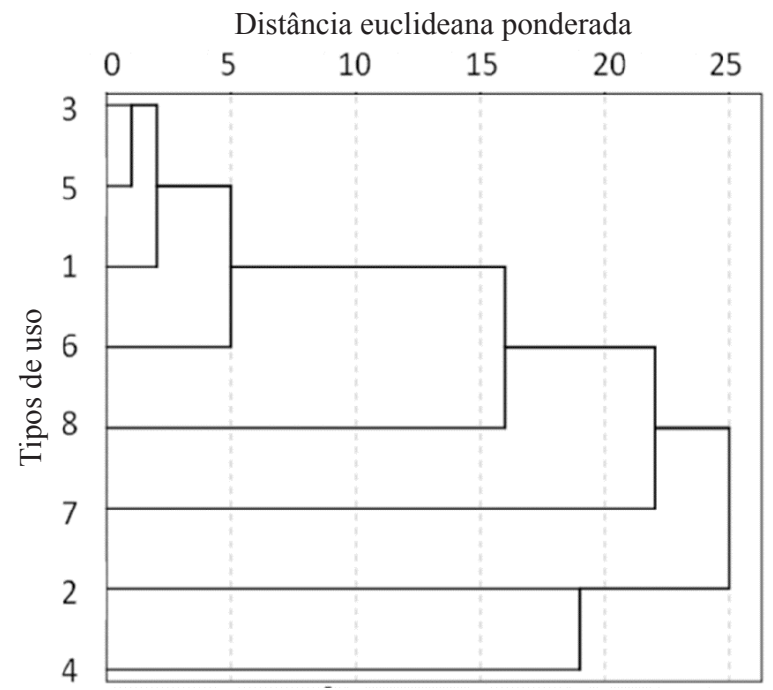

1. Olericultura orgânica; 2. Olericultura convencional; 3. Fruticultura orgânica; 4. Fruticultura convencional; 5. Lavoura orgânica; 6. Lavoura convencional; 7. Viticultura orgânico; 8. Mata nativa

Figura 4. Grupamento hierárquico entre os tratamentos avaliados, sob forma de dendrograma horizontal 
al. (2003) diferenciaram os sistemas de produção convencional e orgânico sendo que, no segundo, ainda ocorreu maior distanciamento dos escores desses sistemas para os obtidos para o uso com mata em relação aos resultados obtidos no presente trabalho.

\section{Conclusões}

1. As características químicas dos solos sob os usos avaliados indicaram, como principais aspectos, os altos valores de $\mathrm{pH}$ e $\mathrm{CE}$, além dos elevados teores de $\mathrm{P}, \mathrm{S}$ e $\mathrm{Zn}$, para os usos mais intensivos (olericultura, fruticultura e viticultura) em sistemas de produção convencionais como orgânicos.

2. O aumento de valores de $\mathrm{pH}$ e CE e os teores de elementos como S,P, Zn e Cu indicam aporte excessivo de adubos minerais e orgânicos passíveis de resultar em problemas ambientais relacionados às altas cargas desses elementos no solo e possível contaminação de mananciais de água.

3. A classificação das áreas amostradas por meio da análise discriminante apresentou boa concordância com a classificação original, expressas pelos índices de exatidão e de Kappa na matriz de erros. $\mathrm{Na}$ análise de componentes principais foram constatadas as maiores semelhanças entre os sistemas orgânicos de olericultura e fruticultura e as lavouras convencionais.

\section{Agradecimentos}

Ao CNPq, pelo apoio financeiro ao projeto; aos escritórios da EMATER e às prefeituras municipais, pela colaboração em todas as etapas da execução; aos agricultores que tiveram suas áreas amostradas, pela participação e hospitalidade.

\section{Literatura Citada}

Alleoni, L. R. F.; Iglesias, C. S. M.; Mello, S.C.; Camargo, O. A. de; Casagrande, J. C.; Lavorenti, N.A. Atributos do solo relacionados à adsorção de cádmio e de cobre em solos tropicais. Acta Scientarium, Agronomy, v.27, p.729-737, 2005.

Andreola, F.; Costa, L. M.; Mendonça, E. S.; Olszevski, N. Propriedades químicas de uma terra roxa estruturada influenciadas pela cobertura vegetal de inverno e pela adubação orgânica e mineral. Revista Brasileira de Ciência do Solo, v.24, p.609-620, 2000.

Bissani, C. A.; Gianello, C.; Camargo, F. A. O.; Tedesco, M. J. Adubos orgânicos, organo-minerais e agricultura orgânica. In: Fertilidade dos solos e manejo da adubação das culturas. Porto Alegre: Editora Metrópole. 2008. Cap.14, p.189-199.

Borges, M. R.; Coutinho, E. L. M. Metais pesados do solo após aplicação de biossólido. II - Disponibilidade. Revista Brasileira de Ciência do Solo, v.28, p.557-568, 2004.

CFS - Comissão de Fertilidade do Solo - RS/SC. Manual de adubação e calagem para os estados do Rio Grande do Sul e de Santa Catarina. 10.ed. Porto Alegre: Sociedade Brasileira de Ciência do Solo/Núcleo Regional Sul, 2004. 404p.
CPRM - Comissão de Pesquisa em Recursos Minerais. Mapa geológico do estado do Rio Grande do Sul. Escala 1:750.000. Projeto Geologia do Brasil ao Milionésimo. 2006.

Correa, R. M.; Freire, M. B. G. S.; Ferreira, R. L. C.; Freire, F. J.; Pessoa, L. G. M.; Miranda, M. A.; Melo, D. V. M. Atributos químicos de solos sob diferentes usos em perímetro irrigado no semiárido de Pernambuco. Revista Brasileira de Ciência do Solo, v.33, p.305-314, 2009.

Costa, F. S.; Bayer, C.; Zanatta, J. A.; Mielniczuk, J. Estoque de carbono orgânico no solo e emissões de dióxido de carbono influenciadas por sistemas de manejo no sul do Brasil. Revista Brasileira de Ciência do Solo, v.32, p.323-332, 2008.

Duarte, A. S.; Airoldi, R. P. S.; Folegatti, M. S.; Botrel, T. A. Efeitos da aplicação de efluente tratado no solo: $\mathrm{pH}$, matéria orgânica, fósforo e potássio. Revista Brasileira de Engenharia Agrícola e Ambiental, v.12, p.302-310, 2012.

EMBRAPA - Empresa Brasileira de Pesquisa Agropecuária. Centro Nacional de Pesquisa de Solos. Manual de Métodos de Análise de Solos. Brasília, 1997. 212p.

FEPAM - Fundação Estadual de Proteção Ambiental. Qualidade das águas da Bacia Hidrográfica do Caí 2002-2011. http:// www.fepam.rs.gov.br/qualidade/qualidade_cai/cai.asp. 10 Mai. 2013.

Figueiredo, S. R.; Giasson, E.; Tornquist, C. G.; Nascimento, P. C. Uso de regressões logísticas múltiplas para mapeamento digital de solos no Planalto Médio (RS). Revista Brasileira de Ciência do Solo, v.32, p.2779-2785, 2008.

Finatto, R. A.; Salamoni, G. Agricultura familiar e agroecologia: Perfil da produção de base agroecológica do município de Pelotas/RS. Sociedade e Natureza, v.20, p.199-217, 2008.

Freddi, O. S.; Ferraudo, A. S.; Centurion, J. F. Análise multivariada na compactação de um Latossolo Vermelho cultivado com milho. Revista Brasileira de Ciência do Solo, v.32, p.953-961, 2008.

Giasson, E.; Bryant, R. B.; Degloria, S. D. GIS-based spatial indices for identification of potential phosphorus export at watershed scale. Journal of Soil and Water Conservation, v.57, p.373-380, 2002.

Gregorich, E. G.; Ellert, B. H. Light fraction and macro organic matter in mineral soils. In: Soil sampling and methods of analysis. Canadian Soc. of Soil Science. Boca Raton: Lewis Publishers, 1993. cap. 22, p.397-407.

Klamt, E.; Burle, M. L.; Badelucci, M.; Arnold, G. Conflitos de uso dos solos do Arroio Cascalho, Portão, RS. Geografia, v.20, p.101-114, 1995.

Lima, H. V; Oliveira, T. S.; Oliveira, M. M.; Mendonça, E. S.; Lima, P. J. B. F. Indicadores de qualidade do solo em sistemas de cultivo orgânico e convencional no semi-árido cearense. Revista Brasileira de Ciência do Solo, v.31, p.1085-1098, 2007.

Nascimento, P. C.; Bissani, C. A.; Levien, R.; Finato, T.; Medeiros, P. S. C. Influência do Uso da terra em atributos físicos e químicos do solo na Serra do Sudeste - RS. Cadernos de Agroecologia, v.8, p.1-6, 2013. 
Novais, R. F.; Smyth, T. J. Extratores. In: Novais, R. F.; Smyth, T. J. Fósforo em solo e planta sob condições tropicais. Viçosa: UFV, 1999. Cap. 9, p.183-211.

Pedron, F.; Poelking, E. L.; Dalmolin, R. S. D.; Azevedo, A. C.; Klamt, E. . A Aptidão de uso da terra como base para o planejamento da utilização dos recursos naturais do município de São João do Polesine, TS. Ciência Rural, v.36, p.105-112, 2006.

Peruch, L. A. M.; Bruna, E. D. Relação entre doses de calda bordaleza e de fosfito potássico na intensidade do míldio e na produtividade da videira cv. 'Goethe'. Ciência Rural, v.38, p.2413-2418, 2008.

Schmitt, D. E.; Comin, J. J.; Gatiboni, L. C.; Tiecher, T.; Lorensini, F.; Mello, G. W. B. Girotto, E.; Guardini, R.; Heinzen, J.; Brunetto, G. Phosphorus fractions in sandy soils of vineyards in southern Brazil. Revista Brasileira de Ciência do Solo, v.37, p.472-481, 2013.

Souza, R. F.; Faquin, V.; Andrade, A. T.; Torres, P. R. F. Formas de fósforo em solos sob influência da calagem e adubação orgânica. Revista Brasileira de Ciência do Solo, v.31, p.15351544, 2007.
Streck, E. V.; Kampf, N.; Dalmolin, R. S. D.; Klamt, E.; Nascimento, P. C.; Schneider, P. Solos do Rio Grande do Sul. Porto Alegre: UFRGS, 2008. 222p.

Tedesco, M. J.; Gianello, C.; Bissani, C. A. ; Bohnen, H.; Volkweiss, S. J. Análises de solos, plantas e outros materiais. 2 ed Porto Alegre: Departamento de Solos da Faculdade de Agronomia, UFRGS, 1995. 174p Boletim Técnico, 5

Theodoro, V. C. M.; Alvarenga, M. I. N.; Guimarães, R. J. Souza, C. A. S. Alterações químicas em solo submetido a diferentes formas de manejo do cafeeiro. Revista Brasileira de Ciência do Solo, v.27, p.1039-1047, 2003.

Vezzani, F. M.; Mielniczuk, J. Uma visão sobre qualidade do solo. Revista Brasileira de Ciência do Solo, v.33, p.743:755, 2009.

Vilar, C. C.; Costa, A. C. S.; Hoepers, A.; Souza Júnior, I. G. Capacidade máxima de adsorção de fósforo relacionada a formas de $\mathrm{Fe}$ e $\mathrm{Al} \mathrm{em} \mathrm{solos} \mathrm{subtropicais.} \mathrm{Revista} \mathrm{Brasileira}$ de Ciência do Solo, v.34, p.1059-1068, 2010.

Waquil, P. D.; Gianluppi, L. D. F. ; Mattos, E. J. As múltiplas dimensões do desenvolvimento rural no Rio Grande do Sul. Ensaios FEE, v.26, p.117-142, 2005. 